\title{
ARTICLE
}

Received 1 Jul 2013 | Accepted 10 Mar 2014 | Published 10 Apr 2014

DOI: $10.1038 /$ ncomms 4605

\section{Bottom-up synthesis of high surface area mesoporous crystalline silicon and evaluation of its hydrogen evolution performance}

\author{
Fang Dai ${ }^{1, \star}$, Jiantao Zai ${ }^{1, \star}$, Ran $\mathrm{Yi}^{1}$, Mikhail L. Gordin ${ }^{1}$, Hiesang Sohn ${ }^{1}$, Shuru Chen ${ }^{1} \&$ Donghai Wang ${ }^{1}$
}

As an important material for many practical and research applications, porous silicon has attracted interest for decades. Conventional preparations suffer from high mass loss because of their etching nature. A few alternative routes have been reported, including magnesiothermic reduction; however, pre-formed porous precursors are still necessary, leading to complicated syntheses. Here we demonstrate a bottom-up synthesis of mesoporous crystalline silicon materials with high surface area and tunable primary particle/pore size via a self-templating pore formation process. The chemical synthesis utilizes salt by-products as internal self-forming templates that can be easily removed without any etchants. The advantages of these materials, such as their nanosized crystalline primary particles and high surface areas, enable increased photocatalytic hydrogen evolution rate and extended working life. These also make the mesoporous silicon a potential candidate for other applications, such as optoelectronics, drug delivery systems and even lithium-ion batteries.

\footnotetext{
${ }^{1}$ Department of Mechanical and Nuclear Engineering, The Pennsylvania State University, University Park, Pennsylvania 16802, USA. * These authors contributed equally to this work. Correspondence and requests for materials should be addressed to D.W. (email: dwang@psu.edu).
} 
$\mathrm{P}$ orous silicon ( $\mathrm{Si}$ ) has long been studied in many fields because of its special physical and chemical properties ${ }^{1}$. For example, porous $\mathrm{Si}$ has been deeply investigated in optoelectronics and sensors owing to its light-emitting properties, drug/gene delivery research has benefited from its high porosity and bio-compatibility ${ }^{2-4}$ and in recent years, porous Si has also been evaluated as a Li-ion battery anode ${ }^{5,6}$. Porous $\mathrm{Si}$ is also considered a promising candidate for hydrogen-generating materials because of its chemical and photocatalytic/ photoelectrochemical reactivities towards water ${ }^{7-9}$. After decades of development, there are two well-established methods to produce porous Si materials, namely, anodisation and stain etching ${ }^{10}$. However, both are top-down methods and suffer from low yield because of their corrosion nature, which generate pores by sacrificing Si. Therefore, high Si mass loss and the need for large quantities of toxic hydrofluoric acid (HF) make these methods high cost and inefficient. In recent years, a few alternative preparations have been reported. One type is magnesiothermic reduction of silica ${ }^{11,12}$. At elevated temperature, porous silica precursor is reduced by magnesium vapour, leaving the pore structure unchanged. Another approach utilizing sodiothermic reduction of zeolite $\mathrm{NaY}$ was reported to obtain higher surface area than the magnesiothermic method ${ }^{13}$. Both reduction processes, however, need pre-formed porous materials as the precursor, which makes the syntheses complicated. A few porous Si/C composite materials have been reported using a chemical vapour deposition method $^{5}$, which is considered an effective bottom-up way to prepare nano-Si materials 5,14 . However, the Si unit in these materials is not porous, although the overall structure is porous and shows good electrochemical performance as a Li-ion battery anode ${ }^{5}$.

More generally, the preparation of porous, especially mesoporous crystalline materials is a big challenge in material chemistry ${ }^{15,16}$. For common mesoporous crystalline metal oxide materials, numerous preparation methods have been reported utilizing many different synthesis techniques after the discovery of mesoporous materials in the 1990s (refs 16-20). In contrast, the syntheses of mesoporous elemental semiconductor materials are highly limited. This is probably due to the complications in the properties of precursors and differences in structure forming chemistry comparing with oxide-based mesoporous materials ${ }^{15}$. The first example of mesoporous germanium (Ge) materials, which were reported separately by Kanatzidis and colleagues using metathesis of $\mathrm{GeCl}_{4}$ with $\mathrm{K}_{4} \mathrm{Ge}_{9}$, and Tolbert and colleagues through an alternative polymer form of $\left(\mathrm{Ge}_{9}^{2-}\right)_{n}$ were not been published until 2006 (refs 21-23). Both syntheses used surfactants as the pore formation templates.

Utilizing reduction or metathesis of halogenides (for example, $\mathrm{GeCl}_{4}$ ) is recognized as an effective solution synthesis of nanocrystalline group IV materials, such as the Ge materials discussed above $21-23$. This kind of metathesis reaction was later expanded to other porous germanium-rich chalcogenide frameworks ${ }^{24}$. A reduction reaction using lithium naphthanide as the reductant was also reported for making nanosized colloidal Ge particles ${ }^{25}$. In comparison, the first synthesis of Si nanocrystals, using $\mathrm{SiCl}_{4}$ and $\mathrm{RSiCl}_{3}(\mathrm{R}=\mathrm{H}$ and octyl $)$ as the coprecursors, was reported by Heath ${ }^{26}$. Further development of this synthesis, using $\mathrm{SiCl}_{4}$ as the only precursor, was initially reported by Kauzlarich and colleagues via Zintl salt metathesis ${ }^{27-29}$. Besides metathesis, other types of solution reactions were also used for $\mathrm{Si}$ nanocrystals via sodium naphthanide and hydride reagents ${ }^{30,31}$. However, unlike for Ge materials, solution synthesis of porous, crystalline Si materials has not yet been reported.

Ideally, the preparation of porous materials should be facile and under ambient conditions. The tuning of surface area and pore size should be feasible and pores should be generated by easily removed templates. It is thus interesting that the only byproducts of the reduction of halogenides are metal salts, which have been used as pore templates in some aerosol syntheses of porous oxide materials, and the influence of salt templates on particle formation was initially studied in depth by Zachariah and colleagues $^{32,33}$. Such salts have excellent thermal stability, which helps maintain the pore structure during heat treatment, and excellent solubility in water, which makes their removal easy. These factors make the salts possible pore template candidates for porous Si materials.

In this work, we report a bottom-up self-templating synthesis of mesoporous crystalline $\mathrm{Si}$ (mPSi) materials. The synthesis utilizes a $\mathrm{Si}$ halogenide precursor $\left(\mathrm{SiCl}_{4}\right)$, which may significantly decrease the cost of the process compared with using crystalline $\mathrm{Si}$ wafers as etching precursors. The pores are produced by salt byproducts as self-forming templates rather than by chemical corrosion of $\mathrm{Si}$, thus providing both high porosity and high mass yield. Moreover, the salt by-products can be easily removed by water instead of necessitating the use of harsh etchants such as $\mathrm{HF}$, as is the case for other methods ${ }^{11}$. The primary particle size, pore size and specific surface area of mPSi can be tuned by adjusting the heat treatment temperature. The resulting MPSi materials show high surface areas, up to $580 \mathrm{~m}^{2} \mathrm{~g}^{-1}$, which to the best of our knowledge is the highest value of all reported mesoporous Si materials $10,11,13,34$. When used for hydrogen $\left(\mathrm{H}_{2}\right)$ generation by chemical reaction with $\mathrm{KOH}$ solution, this allows for an extremely high $\mathrm{H}_{2}$ production rate of $0.095 \mathrm{~g} \mathrm{H}_{2} \mathrm{~s}^{-1} \mathrm{~g}^{-1}$ $\mathrm{Si}\left(1.33 \mathrm{~mol} \mathrm{H}_{2} \mathrm{~s}^{-1} \mathrm{~mol}^{-1} \mathrm{Si}\right)$, which is 30 times higher than the previously reported result ${ }^{7}$. In addition, the high surface area, nanoscale primary particles and uniform mesopores of the mPSi materials allow for a significant improvement in photocatalytic $\mathrm{H}_{2}$ evolution performance compared with the existing literature 9 . A high $\mathrm{H}_{2}$ generation rate, up to $882 \mu \mathrm{mol} \mathrm{H}_{2} \mathrm{~h}^{-1} \mathrm{~g}^{-1} \mathrm{Si}$, is obtained by the optimized mPSi material, and is accompanied by a long working life of at least $55 \mathrm{~h}$. This result not only shows much improved performance over previous reports but also pushes the performance of Si to on par with the current best unloaded (co-catalyst-free) photocatalysts, demonstrating its viability for further investigation ${ }^{35-37}$.

\section{Results}

Synthesis and pore formation mechanism study. Our synthesis route is based on $\mathrm{SiCl}_{4}$ reduction utilizing salt by-products as pore templates. A schematic illustration of the proposed reaction pathway is shown in Fig. 1. In contrast to other syntheses, which use reducing agents such as sodium naphthanide, we have found that employing the alkaline alloy $\mathrm{NaK}$ as a reducing agent leads to formation of amorphous rather than crystalline Si particles under ambient conditions $27,38,39$. Owing to their poor solubility in the solvent, salt by-products and $\mathrm{Si}$ are believed to precipitate out simultaneously, forming a solid matrix. The amorphous $\mathrm{Si}$ is converted to a crystalline framework composed of interconnected primary particles during the following heat treatment, with its growth being restricted by the salt. Similarly, the salt templates are also restricted by the $\mathrm{Si}$ network and thus have mostly uniform size. The material is then washed with water to remove the salt by-products, generating the final porous $\mathrm{Si}$. The pore size, primary particle size, and surface area can be tuned by adjusting the heat treatment temperature.

To study the porous structure formation process, the raw product was isolated immediately after reduction and analysed. The raw product was composed of $\mathrm{Si} /$ salt matrixes that are considered the intermediate product, and some nanosized salt crystals separated from the $\mathrm{Si} /$ salt matrixes (Supplementary Fig. 1 and Supplementary Discussion). The peaks in the X-ray powder 


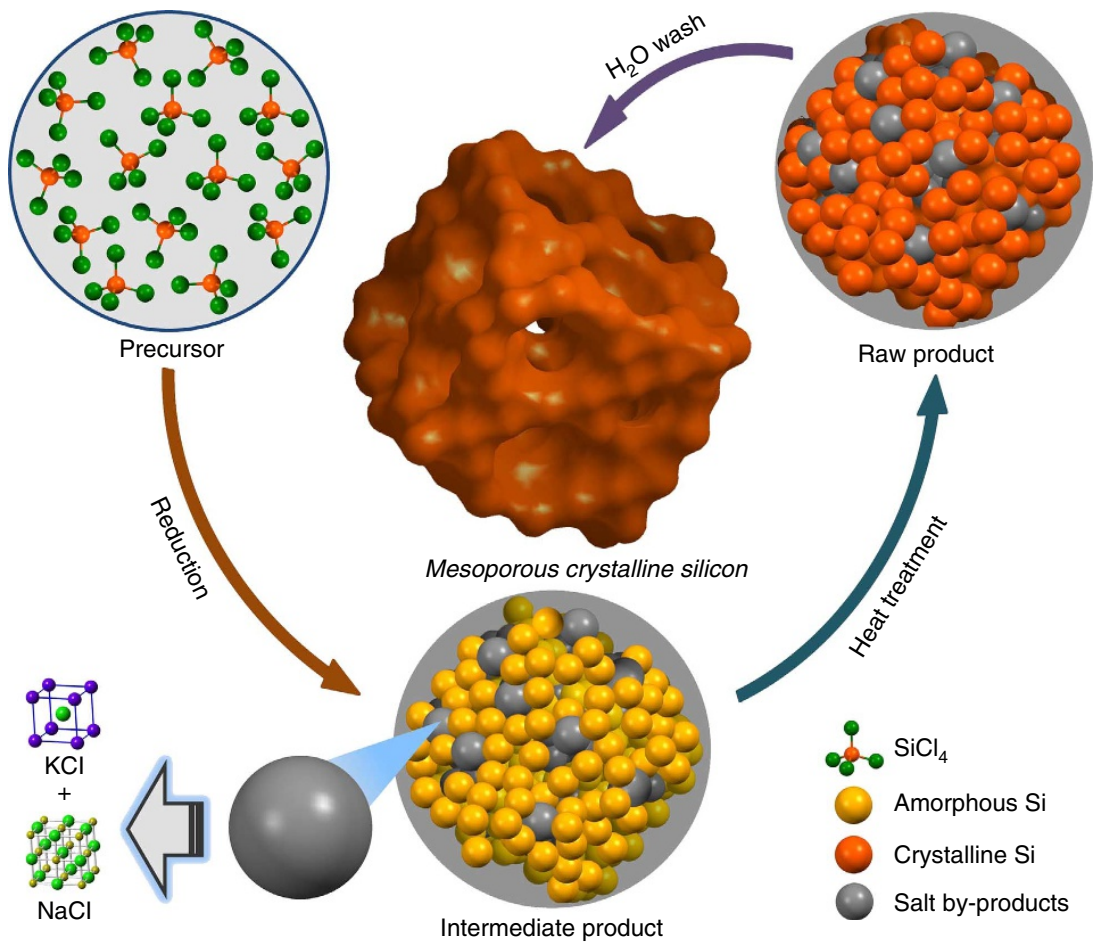

Figure 1 | Scheme of the synthesis route of $\mathbf{m P S i}$. The pictures of the intermediate product and raw product are schematic illustrations that do not exactly reflect the real structures.

diffraction (XRD) pattern of the raw product (Fig. 2a) suggest the formation of crystalline $\mathrm{KCl}$ and $\mathrm{NaCl}$, while the lack of observed Si peaks indicates the formation of amorphous Si. To examine the distribution of $\mathrm{Si}$ and salts in the matrixes, energy-dispersive $\mathrm{X}$-ray spectroscopy (EDS) mapping was carried out on a crosssection of a single particle of the intermediate product (Supplementary Fig. 2). K, Na, $\mathrm{Cl}$ and $\mathrm{Si}$ were found to be uniformly distributed throughout the cross-section of the particle, indicating the even dispersion of $\mathrm{Si}$ and salts in the matrix. The transmission electron microscopy (TEM) image of the intermediate product (Fig. 2b) shows that the mixture is composed of Si particles and salts. The corresponding selected-area electron diffraction pattern (Fig. 2c) also confirms the presence of crystalline salts. $\mathrm{KCl}$ crystallites (about $5-10 \mathrm{~nm}$ size) were observed between the amorphous $\mathrm{Si}$ particles in the highresolution TEM (HRTEM) image (Fig. 2d). In addition, the Brunauer-Emmett-Teller (BET)-specific surface area of the intermediate product is $40 \mathrm{~m}^{2} \mathrm{~g}^{-1}$, which is much smaller than those of the final products (vide infra). The results discussed above confirm that the salt by-products form during the reduction and assist the pore formation, as schematically illustrated in Fig. 1.

Characterization of mPSi. The mPSi materials were obtained by heat treatment of the raw product at different temperatures followed by removal of the salt templates by water. The resulting materials, namely, mPSi- $X$ (where $X$ is the heat treatment temperature in degrees Celsius), were then characterized. The mPSi-600 sample was studied first. The overall particle size of mPSi-600 ranges from 5 to $20 \mu \mathrm{m}$, as shown by SEM imaging (Supplementary Fig. 3), and TEM images in Fig. 3a,b clearly show that the mPSi-600 has a disordered mesoporous structure. The $\mathrm{Si}$ framework consists of interconnected, multicrystalline primary particles with a size of below $10 \mathrm{~nm}$. The crystallite size of mPSi-600 is around $3-5 \mathrm{~nm}$, which is shown in the HRTEM image (Fig. 3c). This is consistent with the crystallite size $(3.6 \mathrm{~nm})$ calculated from the XRD pattern by the Debye-Scherrer equation (Fig. 4a). Nitrogen sorption analysis was also conducted for the mPSi-600 sample. The sorption isotherms shown in Fig. 4b are type-IV isotherm curves with an $\mathrm{H} 1$ hysteresis, indicating the presence of mesopores in the structure ${ }^{40}$. The narrow hysteresis loop with relatively steep and nearly parallel adsorption and desorption branches indicates that the mPSi-600 sample has good pore connectivity and a relatively narrow pore size distribution. The BET-specific surface area for mPSi-600 is $497 \mathrm{~m}^{2} \mathrm{~g}^{-1}\left(1,152 \mathrm{~m}^{2} \mathrm{~cm}^{-3}\right)$. The pore size distribution (inset in Fig. $4 \mathrm{~b}$ ) is centred around $10 \mathrm{~nm}$, as calculated using the BarrettJoynes-Halenda (BJH) method. This is consistent with the size of the salt templates seen in the HRTEM image of the intermediate product (Fig. 2d). The X-ray photoelectron spectrum (XPS) has peaks appearing around 99.8 and $103.5 \mathrm{eV}$, which are assigned primarily to $\mathrm{Si}(0)$ and $\mathrm{Si}(+4)$, respectively (Fig. 4c). The binding energies in between correspond to $\mathrm{SiO}_{x}(0<x<2)^{41-43}$. Further detail on the XPS spectra is presented and discussed in Supplementary Fig. 4, the Methods and the Supplementary Discussion. The surface oxygen content is determined to be around 32 atom\% by XPS (Supplementary Table 1), which is consistent with the oxygen content of 33 atom\% by EDS spectroscopy (Supplementary Fig. 3), suggesting that oxidation of mPSi-600 is uniform both on the surface and within the interior of the overall particle. The appearance of surface oxides, commonly observed in Si nanoparticles, is also verified by the Raman spectrum in which a peak shoulder appears between 300 and $450 \mathrm{~cm}^{-1}$ and is attributed to amorphous $\mathrm{SiO}_{x}(0<x<2)$ and $\mathrm{SiO}_{2}$ (Fig. $\left.4 \mathrm{~d}\right)^{44,45}$. The Raman spectrum of the mPSi-600 also shows a broad peak at $480 \mathrm{~cm}^{-1}$, which indicates the presence of a layer of amorphous Si covering the crystalline core $^{46}$.

By adjusting the heat treatment temperature to 700 and $820^{\circ} \mathrm{C}$, two different mPSi materials (mPSi-700 and mPSi-820) were also 
a

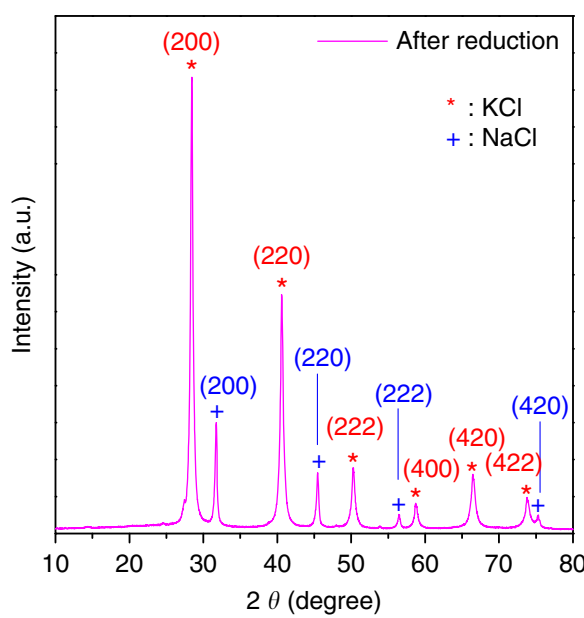

C

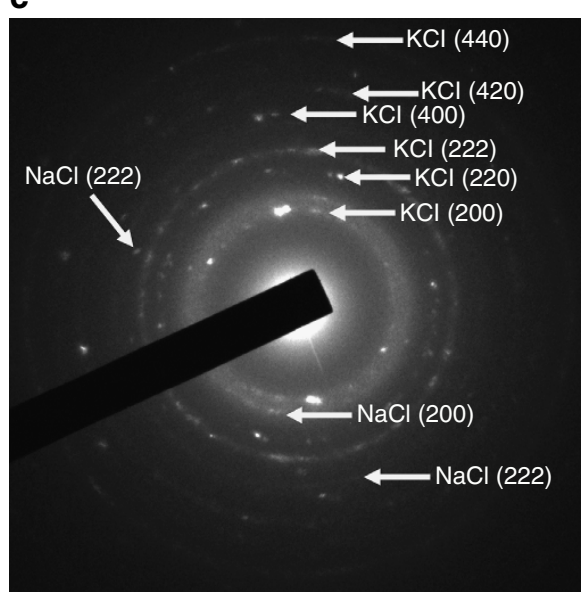

b

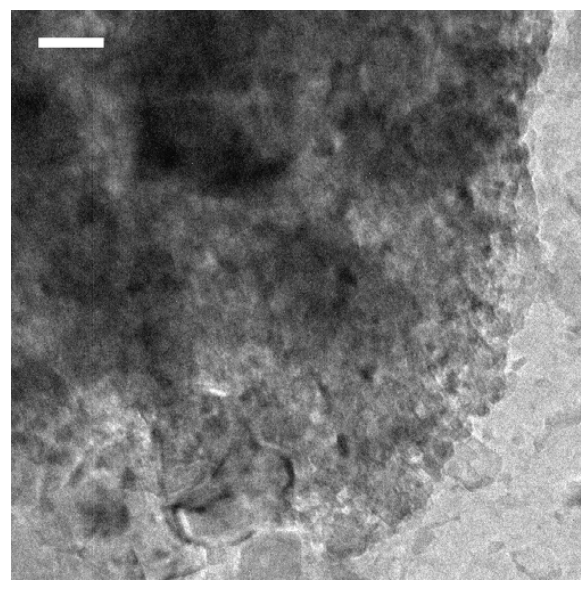

d

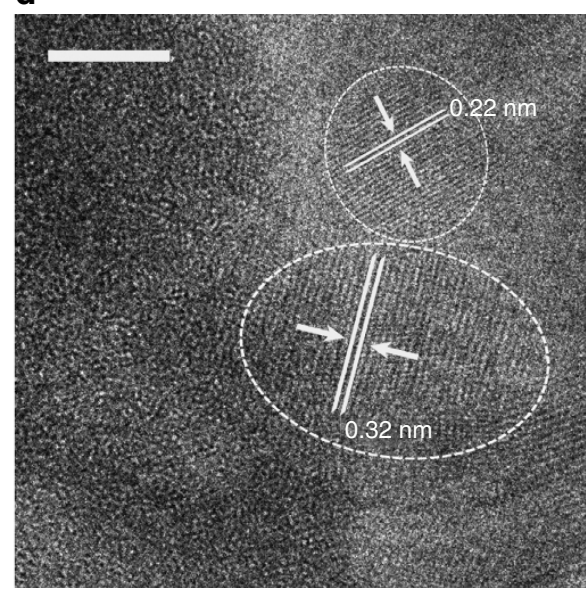

Figure 2 | Characterization of the intermediate products. (a) XRD pattern of the raw products obtained after reduction. The peaks of KCI (JCPDS Card number 41-1476) and $\mathrm{NaCl}$ (JCPDS Card number 05-0628) are labelled. Some of the $\mathrm{NaCl}$ peaks cannot be clearly distinguished owing to overlap with the $\mathrm{KCl}$ peaks. (b) Medium magnification TEM image of the intermediate products. Scale bar, $50 \mathrm{~nm}$. (c) Selected-area electron diffraction (SAED) pattern of the intermediate products. The calculated $d$ spacings from the SAED pattern are consistent with the $d$-spacing values for the corresponding planes of $\mathrm{KCl}$ and $\mathrm{NaCl}$. (d) HRTEM image of the crystalline salt in the intermediate products. The lattice fringes of 0.32 and $0.22 \mathrm{~nm}$

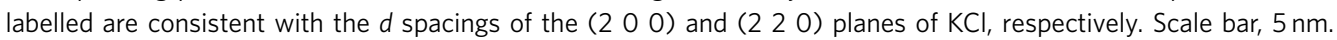

obtained and then characterized. As seen from SEM imaging (Supplementary Fig. 3), the overall particle size of mPSi-700 is similar to that of mPSi-600, in the range of $5-20 \mu \mathrm{m}$, while the mPSi-820 shows both some larger particles of around $30 \mu \mathrm{m}$ in size and some smaller particles. The TEM images of mPSi-700 and mPSi-820 (Fig. 3d-i) show similar disordered mesoporous structures to mPSi-600. However, the sizes of the primary particles are larger ( $\sim 10$ and $10-20 \mathrm{~nm}$, respectively) than those of mPSi-600. The HRTEM images show that the crystallite sizes of $\mathrm{mPSi}-700$ and $\mathrm{mPSi}-820$ are $7-10$ and $10-20 \mathrm{~nm}$, respectively (Fig. 3f,i). This observation is also consistent with the crystallite size of 8.1 and $16 \mathrm{~nm}$ calculated from the XRD patterns. In the Raman spectra, the sharp Si peaks of mPSi-700 and mPSi-820 are at a higher Raman shift $\left(510 \mathrm{~cm}^{-1}\right)$ than the corresponding peak of mPSi-600, which suggests better crystallinity and lower amorphous $\mathrm{Si}$ content than in mPSi-600 (Fig. $4 \mathrm{~d})^{46-48}$. In addition, the lower signal intensity of the Si oxide bands between 300 and $450 \mathrm{~cm}^{-1}$ in the Raman spectra of mPSi-700 and mPSi820 reveals that their oxide content is lower than that of $\mathrm{mPSi}$ 600. The oxygen concentrations of mPSi-700 (about 30 atom\%) and mPSi-820 (about 8 atom\%), determined from their EDS and XPS spectra (Supplementary Fig. 3 and Supplementary Table 1), further indicate a lower oxide content. Since the Si oxides are composed of oxides from the native oxide layer and oxidation products by the water when removing the salts, the lower oxide contents of mPSi-700 and mPSi-820 could be due to their larger particles, better crystallinity and smaller surface area, which help limit oxidation when contacting air and water ${ }^{49}$. Figure $4 \mathrm{~b}$ shows the nitrogen sorption isotherms of $\mathrm{mPSi}-700$ and $\mathrm{mPSi}-820$. BETspecific surface areas for mPSi-700 and mPSi-820 are 321 and $221 \mathrm{~m}^{2} \mathrm{~g}^{-1}$, respectively. The pore size distributions of $\mathrm{mPSi}-700$ and mPSi-820 were calculated by the BJH method. The mPSi-700 shows a similar pore size distribution (centred at $10 \mathrm{~nm}$ ) to that of mPSi-600, while the pore size for mPSi-820 is centred around $20 \mathrm{~nm}$ with a broad pore distribution ranging from 10 to $100 \mathrm{~nm}$ (Fig. 4b, inset). Increased heat treatment temperature leads to $\mathrm{Si}$ grain growth and thus larger primary particle size, resulting in a smaller specific surface area.

Photocatalytic hydrogen evolution of mPSi. Anxiety about the increasingly serious global energy crisis and environment pollution makes producing $\mathrm{H}_{2}$, a clean fuel, more and more attractive ${ }^{50}$. Generating $\mathrm{H}_{2}$ by using sunlight to split water via 
a

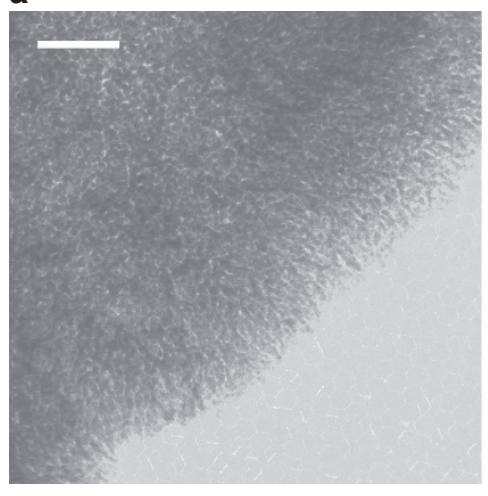

d

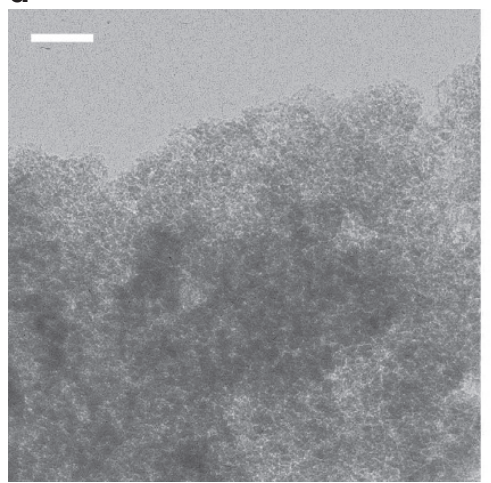

g



b



e

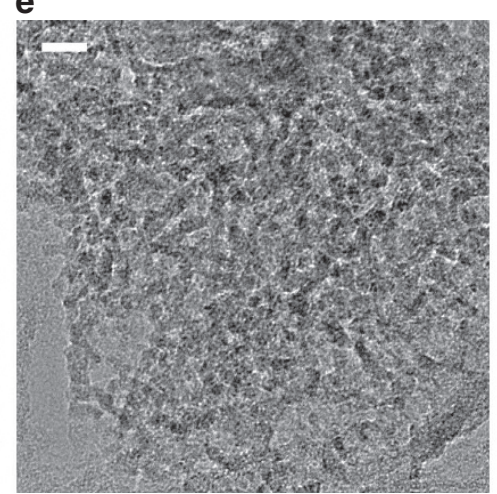

h



c

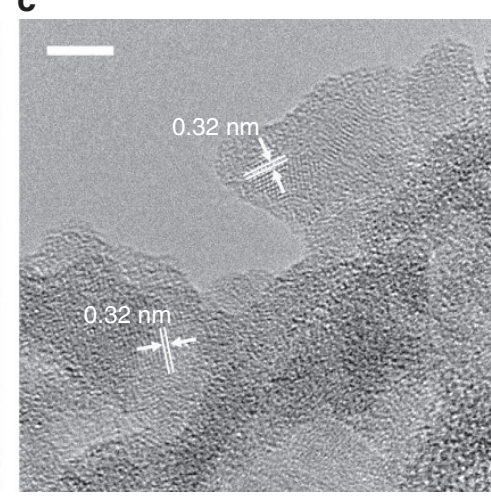

f

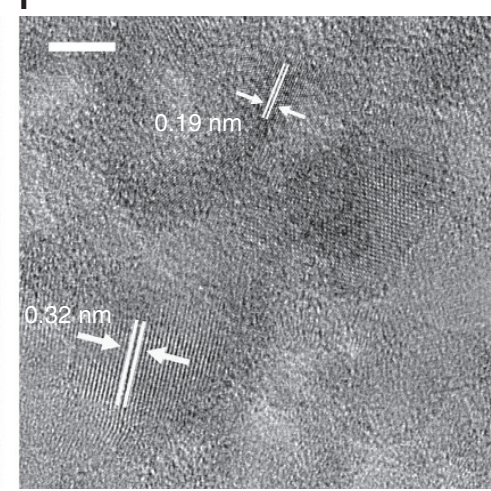

i



Figure 3 | Microscope images of $\mathbf{m P S i}$ materials. (a-c) Low, medium magnification TEM and HRTEM images of mPSi-600. The lattice fringes of $0.32 \mathrm{~nm}$ labelled are consistent with the $d$-spacing value of the (111) plane of silicon (JCPDS Card number 27-1402). Scale bar, 100, 20 and $5 \mathrm{~nm}$, respectively. (d-f) Low, medium magnification TEM and HRTEM images of mPSi-700. The lattice fringes of 0.32 and $0.19 \mathrm{~nm}$ labelled are consistent with the $d$-spacing values of the (1 111 ) and (2 20 ) planes of silicon, respectively. Scale bar, 100, 20 and $5 \mathrm{~nm}$, respectively. (g-i) Low, medium magnification TEM and HRTEM images of mPSi-820. The lattice fringes of $0.32 \mathrm{~nm}$ labelled are consistent with the $d$-spacing value of the (111) plane of silicon. Scale bar, 100, 20 and $5 \mathrm{~nm}$, respectively.

photocatalytic methods is particularly promising. Photocatalytic $\mathrm{H}_{2}$ generation takes advantage of some of the unique abilities of semiconductors; after absorbing photons, electrons (holes) can be generated at the conduction band (valence band) of semiconductors. If the generated electrons and holes have enough energy to overcome the energetic barriers of both water reduction and oxidation and any overpotentials, photocatalytic water splitting will be realized ${ }^{51}$. Some oxide-based catalysts, such as $\mathrm{TiO}_{2}$, have been extensively studied since the 1970s and show good stability in this photocatalytic process. However, most of them show acceptable activity only under ultraviolet light owing to their large band gaps ${ }^{51,52}$. Although the band gaps of most sulphide-based catalysts (for example, CdS, $\mathrm{ZnS}-\mathrm{CuInS}_{2}$ and $\mathrm{ZnS}-\mathrm{AgInS}_{2}$ ) allow them to utilize visible light, the stabilities of these materials are poor ${ }^{51,52}$. This is mainly due to the reaction between sulphides and photogenerated holes in the catalysts. In addition, those with acceptable activity contain either the highly toxic element $\mathrm{Cd}$ or rare and expensive elements like In. Untill now, an efficient material for photocatalytic water splitting under visible light irradiation has not been discovered ${ }^{53}$.

$\mathrm{Si}$ is one of the most promising candidates in the solar $\mathrm{H}_{2}$ production area. The narrow $1.17 \mathrm{eV}$ band gap of $\mathrm{Si}$ is appropriate for utilizing the solar spectrum, allowing it to capture photons up to the near-infrared region. In addition, it is the most abundant element on earth, precluding future problems of material scarcity. Moreover, thanks to the development of Sibased solar cells, the fundamental semiconductor physics and device fabrication processes of Si have been thoroughly studied. 



Figure 4 | Characterization of mPSi materials. (a) XRD patterns. (b) Nitrogen sorption isotherms and BJH pore size distributions (inset). (c) XPS spectra. (d) Raman spectra.

The development of nanostructured $\mathrm{Si}$ materials has also extended the use of $\mathrm{Si}$ into artificial photosynthesis, such as $\mathrm{CO}_{2}$ fixation and $\mathrm{H}_{2}$ generation ${ }^{54}$.

Solar $\mathrm{H}_{2}$ generation can take place via photoelectrochemical or powder photocatalytic systems. For photoelectrochemical solar $\mathrm{H}_{2}$ evolution, photoelectrodes based on $\mathrm{Si}$ have been proved to be efficient $^{55-57}$. However, the photoelectrochemical process usually needs external bias (provided by an external power supply) to surpass the overpotential, which hinders its application at large scales and introduces a parasitic energy cost. On the other hand, powder photocatalytic systems are considered better in large-scale solar water splitting owing to their simplicity ${ }^{51}$. Unfortunately, there are few reports on photocatalytic solar $\mathrm{H}_{2}$ evolution by $\mathrm{Si}$ materials ${ }^{9}$. The limitation of such systems is mainly the small energy gap between the conduction band edge and the $\mathrm{H}^{+} / \mathrm{H}_{2}$ potential, as well as the short working life commonly exhibited by conventional Si materials 9,58 .

All mPSi materials showed wider band gaps $(1.33-1.63 \mathrm{eV})$ than that of bulk Si $(1.17 \mathrm{eV})$; band gaps were calculated according to ultraviolet-visible diffuse reflectance spectra (Fig. 5a-c). The expanded band gaps of the mPSi materials, which shift the conduction band to a more negative position and may thus facilitate $\mathrm{H}_{2}$ evolution, are due to quantum confinement. The band gap crystallite size correlations are also consistent with previous theoretical calculations (Supplementary
Discussion $)^{58-60}$. The quantum-confinement effects were confirmed by photoluminescence spectroscopy (Supplementary Fig. 5 and Supplementary Discussion) ${ }^{61}$. Figure $5 \mathrm{~d}$ shows the typical reaction time course of the photocatalytic $\mathrm{H}_{2}$ evolution of different unloaded mPSi materials. All mPSi materials showed better photocatalytic $\mathrm{H}_{2}$ evolution activity than commercially available Si nanopowder $\left(191,337\right.$ and $67 \mu \mathrm{mol} \mathrm{H}_{2} \mathrm{~h}^{-1} \mathrm{~g}^{-1} \mathrm{Si}$ in $7 \mathrm{~h}$ for $\mathrm{mPSi}-600,700$ and 820 , respectively, versus $29 \mu \mathrm{mol}$ $\mathrm{H}_{2} \mathrm{~h}^{-1} \mathrm{~g}^{-1} \mathrm{Si}$ in $7 \mathrm{~h}$ for commercial Si, Fig. 5e). However, mPSi600 showed a lower photocatalytic $\mathrm{H}_{2}$ evolution rate $(191 \mu \mathrm{mol}$ $\mathrm{H}_{2} \mathrm{~h}^{-1} \mathrm{~g}^{-1} \mathrm{Si}$ in $\left.7 \mathrm{~h}\right)$ than mPSi-700 $\left(337 \mu \mathrm{mol} \mathrm{H}_{2} \mathrm{~h}^{-1} \mathrm{~g}^{-1} \mathrm{Si}\right.$ in $7 \mathrm{~h}$ ), although the surface area of mPSi-600 is much higher than that of mPSi-700.

Refinement of mPSi-600 and photocatalytic performance. Higher surface area can improve photocatalytic activity by providing more surface active sites. However, the photocatalytic activity also depends on the particle size, surface structure and crystallinity of the material, which greatly affect the rate of the charge generation, separation, migration and recombination steps $^{51}$. Although mPSi-600 has a higher surface area, its photocatalytic $\mathrm{H}_{2}$ evolution rate is lower than that of mPSi-700. The worse photocatalytic performance of mPSi-600 is probably because of its worse crystallinity and higher content of surface 
a

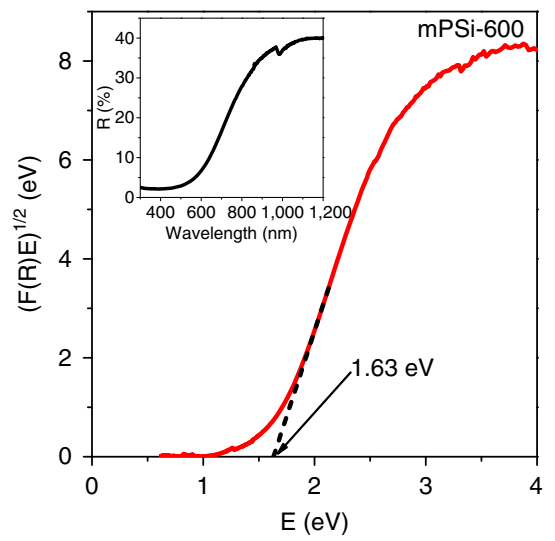

C

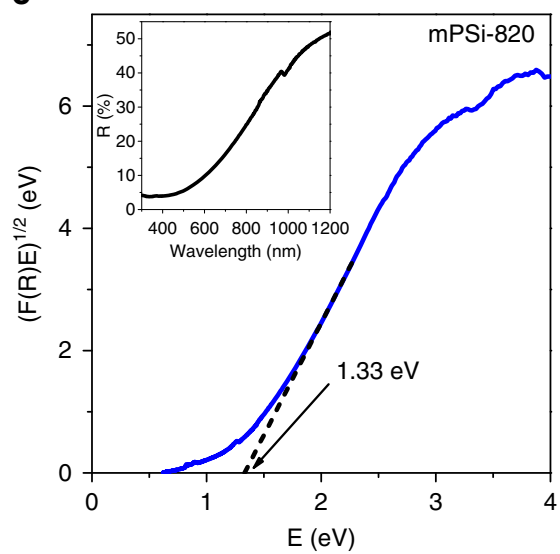

b

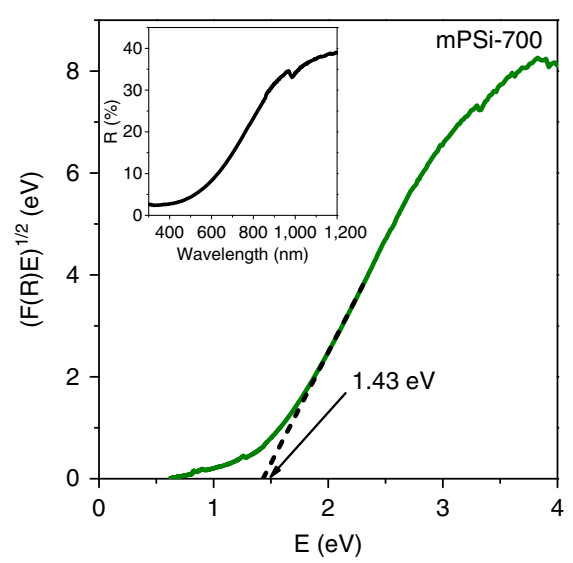

d

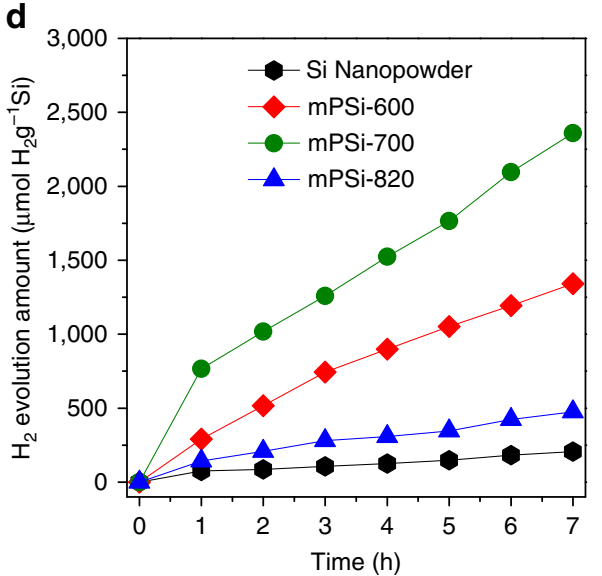

Figure 5 | Optical properties and photocatalytic performance. (a-c) Optical band gaps and ultraviolet-visible diffuse reflectance spectra (inset) of mPSi materials. (d) Typical reaction time course of the photocatalytic $\mathrm{H}_{2}$ evolution of different unloaded porous Si materials and Si nanopowder under $300 \mathrm{~W}$ xenon light.

oxides, which may decrease the amount of effective surface active sites, prevent the migration of photogenerated charges and increase the recombination of the photogenerated electrons and holes $^{51}$.

To confirm this, mPSi-600 was further treated to remove the surface oxides, and the resulting refined material, namely, $\mathrm{mPSi}$ $600 \mathrm{R}$, was then characterized. The overall particle size of mPSi600R is similar to that of $\mathrm{mPSi}-600$, as observed in the SEM image (Supplementary Fig. 3). The TEM images (Fig. 6a) show a similar primary particle size to that of mPSi-600 (below $10 \mathrm{~nm}$ ). More crystallites are observed in the HRTEM image (Fig. 6b) and the crystallite size ranges from around $2-5 \mathrm{~nm}$, which is consistent with the result $(3.2 \mathrm{~nm})$ calculated from the XRD pattern (Fig. 6c). The sorption isotherm of mPSi-600R is similar to that of mPSi-600, having type-IV isotherm curves with an $\mathrm{H} 1$ hysteresis, and the $\mathrm{BJH}$ pore size distribution is also very similar (Fig. 6d). However, the BET surface area of mPSi-600R is slightly increased to $580 \mathrm{~m}^{2} \mathrm{~g}^{-1}$. The XPS spectrum (Fig. 6e) shows a strong decrease in the intensity of the peak at $103.5 \mathrm{eV}$ as well some decrease in area corresponding to $\mathrm{SiO}_{x}$, which indicates a lower oxide content in the material. The oxygen concentration was found to be about 11 atom\% based on EDS, which is consistent with the content found from the XPS spectrum (Supplementary Fig. 3 and Supplementary Table 1). In the Raman spectrum (Fig. 6f), the sharpness of the major Si peak and its shift to $500 \mathrm{~cm}^{-1}$, along with the much decreased intensity of the oxide peak at about $350 \mathrm{~cm}^{-1}$, further confirm the less oxidized nature of $\mathrm{mPSi}-600 \mathrm{R}$. The band gap of $\mathrm{mPSi}-600 \mathrm{R}$ was found to be $1.62 \mathrm{eV}$, as calculated according to its ultraviolet-visible diffuse reflectance spectrum (Supplementary Fig. 6). A comparison of all band gaps calculated in this manner with values predicted based on theoretical models in the literature is presented in Supplementary Fig. 7 and the Supplementary Discussion.

The $\mathrm{H}_{2}$ evolution performance of the refined sample was also tested. The photocatalytic activity of mPSi-600R was much better than that of the other mPSi samples, as summarized in Supplementary Fig. 8 and Supplementary Table 2, allowing for an average $\mathrm{H}_{2}$ generation rate of $882 \mu \mathrm{mol} \mathrm{H}_{2} \mathrm{~h}^{-1} \mathrm{~g}^{-1} \mathrm{Si}$ over $7 \mathrm{~h}$ of testing (Fig. 6g), which is comparable to the best reported unloaded photocatalysts (for example, $\mathrm{MoS}_{2} / \mathrm{TiO}_{2},(\mathrm{AgIn})_{x} \mathrm{Zn}_{2}$ $\left.(1-x) \mathrm{S}_{2}, \mathrm{Cu}_{3} \mathrm{SnS}_{4}\right)$ for solar $\mathrm{H}_{2}$ evolution ${ }^{35-37}$.

The photocatalytic activities of mPSi-600R under different illumination conditions were also studied. Unlike other tested samples, mPSi-600R showed an obvious reactivity towards water even under dark conditions (Fig. 6g). In general, the natural oxidation of $\mathrm{Si}$ by water, which generates $\mathrm{H}_{2}$, is slow ${ }^{62}$. The increased reaction rate of $\mathrm{mPSi}-600 \mathrm{R}$ is attributed to its enlarged surface area, which provides extra contact between the $\mathrm{Si}$ and water. This relationship between surface area and reaction rate is further demonstrated by a chemical reaction of mPSi-600R with $\mathrm{KOH}$ aqueous solution (Supplementary Fig. 9). An extremely high average $\mathrm{H}_{2}$ generation rate of $0.095 \mathrm{~g} \mathrm{H}_{2} \mathrm{~s}^{-1} \mathrm{~g}^{-1} \mathrm{Si}$ (1.33 $\mathrm{mol} \mathrm{H}_{2} \mathrm{~s}^{-1} \mathrm{~mol}^{-1} \mathrm{Si}$ ) was obtained, which is about 30 times the highest reported result $\left(0.003 \mathrm{~g} \mathrm{H}_{2} \mathrm{~s}^{-1} \mathrm{~g}^{-1} \mathrm{Si}\right)^{7}$. In addition, mPSi-600R showed obvious photocatalytic reactivity under visible light (Fig. 6g). In contrast, no $\mathrm{H}_{2}$ was generated 
a

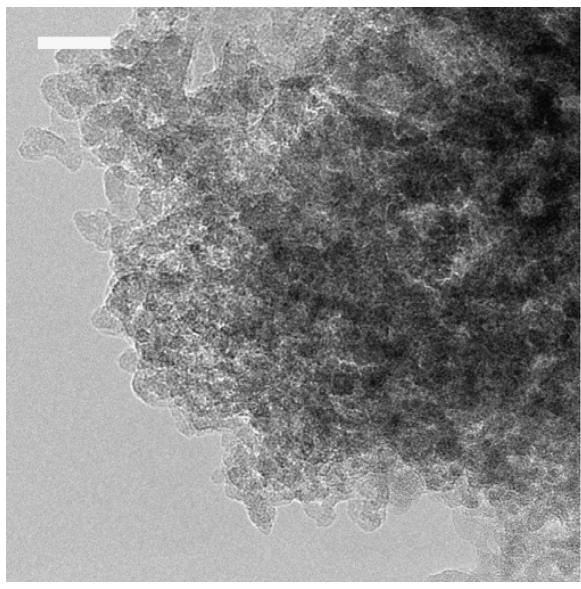

b



C

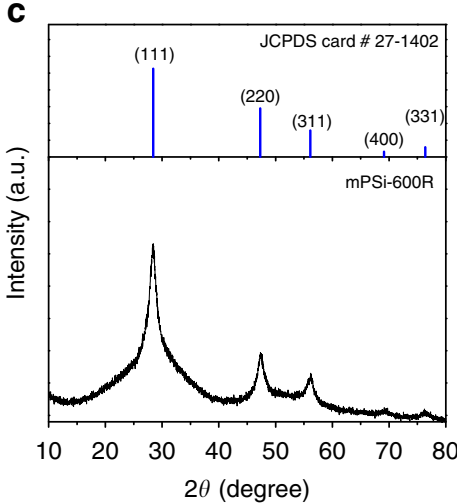

$\mathbf{f}$

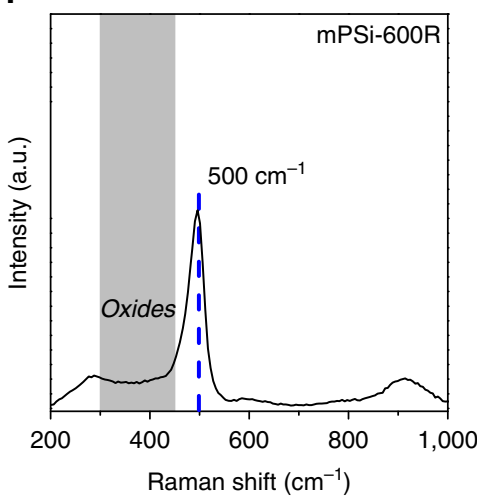

d

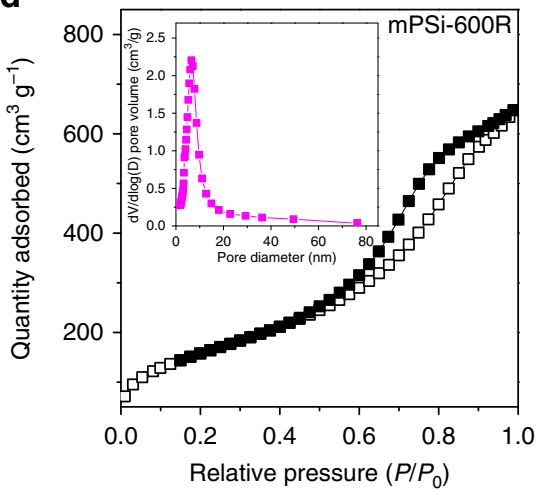

$\mathbf{9}$



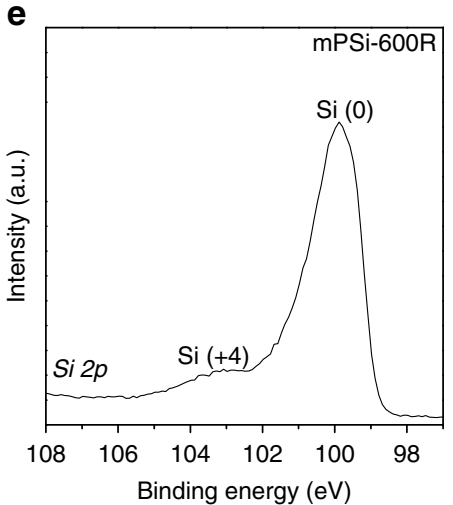



Figure 6 | Characterization and photocatalytic performance of $\mathbf{m P S i}-\mathbf{6 0 0 R}$. (a,b) Medium magnification TEM and HRTEM images. The lattice fringes of $0.32 \mathrm{~nm}$ labelled are consistent with the $d$-spacing value of the (111) plane of silicon. Scale bar, 20 and $5 \mathrm{~nm}$, respectively. (c) XRD patterns.

(d) Nitrogen sorption isotherms and BJH pore size distribution (inset). (e) XPS spectrum. (f) Raman spectrum. (g) Comparison of $\mathrm{H}_{2}$ evolution activities of mPSi-600R under different light conditions. (h) Cycling ability of mPSi-600R under different light conditions.

under visible light by Si nanopowder ${ }^{9}$. The results of these tests, along with other $\mathrm{H}_{2}$ generation tests mentioned previously, were found to be highly repeatable, as shown in Supplementary Figs 9 and 10, and the Methods. The mPSi-600R also showed much longer working life compared with the previously reported result, in which the Si photocatalyst died after $5 \mathrm{~h}^{9}$. After $55 \mathrm{~h}$ of cyclic operation (three cycles, $21 \mathrm{~h}$ effective working time, Fig. $6 \mathrm{~h}$ ), mPSi-600R still showed acceptable photocatalytic $\mathrm{H}_{2}$ evolution rate $\left(\sim 400 \mu \mathrm{mol} \mathrm{H} \mathrm{H}^{-1} \mathrm{~g}^{-1} \mathrm{Si}\right)$. To the best of our knowledge, the necessary cycle life for industrial application of photocatalytic $\mathrm{H}_{2}$ evolution is not known. Nonetheless, our results show that porous $\mathrm{Si}$ photocatalysts have promising performance to go along with the other benefits of using $\mathrm{Si}$, and are worth investigating further.

\section{Discussion}

The preparation of mPSi is composed of two key processes, which are reduction and heat treatment. The salt by-products are bi-functional during the synthesis. In the first step, these salts and $\mathrm{Si}$ are generated by the reduction of $\mathrm{SiCl}_{4}$ and precipitate out owing to their poor solubility in toluene solvent. The exact nature of the precipitation process and following aggregation process is difficult to directly characterize; however, several factors are 
expected to direct these processes. According to the reaction equation, four equivalents of metal salt are generated for each equivalent of $\mathrm{Si}$. In addition, $\mathrm{NaK}$ is a strong reducing agent, and $\mathrm{SiCl}_{4}$ is a highly reactive precursor, so the reduction reaction is expected to be kinetically fast. Because of the larger quantity of salt formed and the fast kinetics of both salt and Si formation, the $\mathrm{Si}$ and salts simultaneously aggregate together to form a matrix. The salts then, in turn, act as pore templates; TEM images (Fig. 2d) clearly show that the salt crystals fill the space between $\mathrm{Si}$ particles, which later becomes the pores. Similar salt-templating processes have previously been reported in aerosol syntheses of porous oxide materials ${ }^{32,33}$. Although the salt is believed to serve as the pore template, the pores are not expected to perfectly replicate the shape of the salt crystallites. This is because the structure is formed by aggregation of similarly sized $\mathrm{Si}$ and salt particles, which produces extra voids between particles and can distort the final pore shape from the template shape.

In the following heat treatment, the salts act as a pore filler to support the structure. They not only maintain the pores but also help restrict the growth of the Si framework owing to their good thermal stability. Concurrently, the growth of salt crystallites in mPSi-600 and mPSi-700 is significantly restricted by the $\mathrm{Si}$ framework, leading to similar pore sizes for these two samples. However, once the heating temperature reaches the melting points of the salts (melting point, $\mathrm{KCl}: 770{ }^{\circ} \mathrm{C}, \mathrm{NaCl}: 801{ }^{\circ} \mathrm{C}$ ), the salts melt and the growth of the $\mathrm{Si}$ becomes unrestricted. Thus, the resulting distribution of both Si primary particle size and pore size in mPSi-820 is not as uniform as in the other mPSi materials. This result indicates that the heat treatment temperature must be kept below $770^{\circ} \mathrm{C}$ to obtain a uniform pore structure. After heat treatment, the salts can easily be removed by water, which makes the synthesis less complicated than other templating methods.

The strong Si-Cl bonding $\left(\sim 380 \mathrm{~kJ} \mathrm{~mol}^{-1}\right)$ makes the reduction reaction of $\mathrm{SiCl}_{4}$ extremely harsh; only reductants that have enough reducing potential can cause this reaction to occur. According to the published results, only a few strong reducing reagents, such as sodium/sodium naphthanide and lithium/ alkyllithium, work for this reaction. The $\mathrm{NaK}$ alloy used in this work is the only reagent so far that can create the desired porous crystalline $\mathrm{Si}$ materials. However, $\mathrm{NaK}$ is also an aggressive reagent and has similar limitations (for example, violent reaction with moisture) as the other reagents for $\mathrm{SiCl}_{4}$ reduction. A milder/safer reagent that provides a balance between stability/safety and reactivity for the $\mathrm{SiCl}_{4}$ reduction process would thus be a very desirable outcome from a future study.

The mPSi materials possess several traits that make them attractive for photocatalytic $\mathrm{H}_{2}$ generation. As an indirect band gap semiconductor, the absorption coefficient of $\mathrm{Si}$ is low in the visible light region. However, the mesoporous structure of the mPSi materials can help increase efficiency of light absorption and partially make up for this deficiency 63,64 . Critically, the demonstrated quantum confinement effects derived from the nanoscale crystallite sizes of mPSi lead to enlarged band gaps, which shift the conduction band to a more negative position and thus facilitate the $\mathrm{H}_{2}$ evolution process ${ }^{58}$. In addition, the small particle sizes shorten the migration distances of photogenerated charges to the surface active sites, reducing recombination. The high carrier mobility of $\mathrm{Si}$ also benefits charge migration and facilitates photocatalysis ${ }^{65}$. Concurrently, the large surface area provides abundant reaction sites for $\mathrm{H}_{2}$ evolution. These advantages grant the mPSi materials photocatalytic activities that are far superior to conventional Si nanoparticles.

The surface state of the photocatalysts also plays a major role in their performance. The better $\mathrm{H}_{2}$ evolution performance of mPSi600R compared with mPSi-600 confirms that the surface state (here, oxide content) is very important to the photocatalytic activity, as the surface state can significantly change the amount of surface active sites and the migration of photogenerated charges $^{51}$. On the basis of the convenient synthesis and promising $\mathrm{H}_{2}$ evolution reactivity, the mPSi materials show great potential for full photocatalytic water splitting by pairing with an $\mathrm{O}_{2}$-evolution semiconductor $\left(\mathrm{BiVO}_{4}, \mathrm{TiO}_{2}\right.$, even $n$-type $\left.\mathrm{Si}\right)$ using a Z-scheme photocatalytic system ${ }^{51,66}$.

In conclusion, we have developed a bottom-up synthesis of mPSi materials. The wet chemical synthesis avoids using external templates, so highly porous Si materials can be obtained entirely without etching. The oxide content can be significantly decreased by using a comparatively mild etching approach. This low-cost process is facile and efficient, and allows tuning of properties such as the surface area, pore size and primary particle size. Excellent chemical $\mathrm{H}_{2}$ generation rate can be obtained, thanks to the high surface areas. More importantly, the high surface areas and mesoporous structure combined with the nanosized, crystalline primary particles enable much improved $\mathrm{H}_{2}$ evolution rate and extended working life compared with the previously reported result. The performance is on par with the best reported unloaded photocatalysts for $\mathrm{H}_{2}$ evolution ${ }^{35-37}$. Moreover, this synthesis method has a potential to be extended to other group IV elements to prepare corresponding porous materials. The advantages of this material also make it a possible candidate for other applications, such as optoelectronics, drug delivery systems and even Li-ion batteries.

\section{Methods}

Preparation of mPSi. The as-prepared NaK alloy $(6 \mathrm{~g})$ was added to $200 \mathrm{ml}$ of toluene solution of anhydrous $\mathrm{SiCl}_{4}(4 \mathrm{ml}$, Aldrich $99.998 \%)$ in a glovebox filled with Ar. (Caution: the NaK alloy is highly reactive and should be prepared with care under an Ar atmosphere.) The reaction mixture was stirred by magnetic stirring overnight under Ar. Twenty millilitres of diethyl ether solution of hydrogen chloride ( $2 \mathrm{M}$, Aldrich) was added to quench the remaining $\mathrm{NaK}$. The raw products were collected by filtration and heated in a tube furnace at different temperatures (for example, 600,700 and $820^{\circ} \mathrm{C}$, at $15^{\circ} \mathrm{C} \mathrm{min}{ }^{-1}$ elevated rate) for $30 \mathrm{~min}$ under Ar flow. The yields of mPSi-600, 700 and 820 after calcination are nearly $100 \%$, based on the stoichiometrically expected yield (1:4 Si:MCl ratio in the product, $\mathrm{M}=\mathrm{Na}, \mathrm{K})$. The salt by-products were removed by washing with deionized (DI) water. The final product was obtained by filtration and dried under vacuum before use. The final yield of mPSi-600 is $91 \%$. The yields of mPSi-700 and mPSi-820 are 89 and $88 \%$ based on $\mathrm{Si}$.

Refinement of mPSi-600. Typically, $400 \mathrm{mg}$ of mPSi-600 was immersed in $50 \mathrm{ml}$ $5 \mathrm{wt} \% \mathrm{HF}$ solution (with $1 \mathrm{ml}$ ethanol added) for $1 \mathrm{~h}$. The resulting material was collected by filtration and washed by degased DI water. The final product was dried at $60^{\circ} \mathrm{C}$ under vacuum. Owing to its high sensitivity towards light and moisture, the mPSi-600R was stored in a light-shielded container under Ar. The yield of $\mathrm{mPSi}-600 \mathrm{R}$ is $71 \%$ based on mPSi-600.

Characterization. The samples were characterized on a Rigaku Dmax-2000 X-ray powder diffractometer (XRD) with $\mathrm{Cu} \mathrm{K} \alpha$ radiation $(\lambda=1.5418 \AA)$. The operating voltage and current were kept at $40 \mathrm{kV}$ and $30 \mathrm{~mA}$, respectively. The size and morphology of products were determined by a JEOL-1200 TEM, JEOL-2010 TEM and HRTEM, and FEI Nova NanoSEM 630 scanning electron microscope (SEM and EDS mapping). Owing to the sensitivity of the mPSi samples (specifically, mPSi-600 and mPSi-600R), the TEM samples were prepared by dropping the sample (dispersed in anhydrous hexane) onto the TEM grids inside the glovebox, and allowing the solvent to dry. The as-prepared grids were then transferred to the microscope facility in an air-tight container and were exposed to air for less than $1 \mathrm{~min}$ before TEM imaging. For the pore structure analysis, nitrogen sorption analyses were carried out at $77 \mathrm{~K}$ with a Micrometrics ASAP 2020 analyser (Micrometrics Instrument Corporation, Norcross, GA). Specific surface areas were calculated by the BET method using the adsorption branch in a relative pressure range from 0.04 to 0.25 . The pore size distribution was calculated from the desorption branch of the $\mathrm{N}_{2}$ isotherm with the $\mathrm{BJH}$ method. X-ray photoelectron spectroscopy (XPS) was conducted with a Kratos Analytical Axis Ultra XPS using monochromatic $\mathrm{Al} \mathrm{K} \alpha$ radiation. High-resolution spectra were recorded with a pass energy of $20 \mathrm{eV}$ in $0.1 \mathrm{eV}$ steps. Binding energies were corrected with respect to the binding energy of the $\mathrm{C} 1 \mathrm{~s}$ peak at $284.8 \mathrm{eV}$. Raman spectroscopy was conducted with a WITec CMR200 confocal Raman instrument. Photoluminescence spectroscopy was performed using a Horiba Jobin Yvon Fluorolog 3-21 spectrometer. Diffuse reflectance ultraviolet-visible spectroscopy was 
performed by a Perkin-Elmer Lambda 950 spectrometer with a Labsphere DRACA-30I accessory.

Fitting of XPS peak components. Peak fitting was performed using the CasaXPS software, and was based on assumption of only $\mathrm{Si}$ and oxidized $\mathrm{Si}$ being present. The five Si oxidation states were fit with symmetric Gaussian/Lorentzian product peaks with a mixing parameter of 10 (mixing of 0/100 gives a pure Gaussian/pure Lorentzian line shape). Positions for the $\mathrm{Si}(0), \mathrm{Si}(+1), \mathrm{Si}(+2), \mathrm{Si}(+3)$ and $\mathrm{Si}(+4)$ components were chosen based on literature values and allowed to vary by $0.1 \mathrm{eV}$ during fitting, while the peak width was allowed to vary approximately within the bounds established by the literature ${ }^{42,43,67-69}$.

Photocatalytic hydrogen evolution. Photocatalytic $\mathrm{H}_{2}$ evolution was performed in a gas-closed top window (quartz glass) Pyrex cell with a side septum neck for sampling, using a 300-W Xe lamp as the light source. The effective area of the cell is $40.7 \mathrm{~cm}^{2}$. gas samples $(0.1 \mathrm{ml})$ were taken periodically and analysed for $\mathrm{H}_{2}$ using a HP5890II gas chromatograph, with a thermal conductivity detector and a $15-\mathrm{m}$ Rt-Mseive $5 \mathrm{~A}$ column (Restek). In all experiments, around $0.02 \mathrm{~g}$ of catalyst was added into the reaction cell and purged with argon for $30 \mathrm{~min}$. Separately, $60 \mathrm{ml}$ of DI water mixed with $10 \mathrm{ml}$ of the sacrificial agent methanol (for scavenging the photogenerated holes) were also purged with $\mathrm{Ar}$ for $30 \mathrm{~min}$. The water/methanol mixture was then added to the catalyst under Ar to begin the $\mathrm{H}_{2}$ evolution reaction. Temperature for all photocatalytic reactions was kept at $25 \pm 5^{\circ} \mathrm{C}$. A controlled experiment was carried out before characterization, and no appreciable $\mathrm{H}_{2}$ was detected without photocatalyst. To confirm the reproducibility of test results, the photocatalytic $\mathrm{H}_{2}$ evolution tests of different samples and of mPSi-600R under different light conditions were repeated three times. All tests are largely consistent with one another, barring fairly minor variations (Supplementary Fig. 10). The small differences observed come from minor weighing, sampling and instrumental errors. The average $\mathrm{H}_{2}$ evolution comparison among all test samples is shown in Supplementary Fig. 8. Supplementary Table 2 shows a summary of primary particle size, surface area, band gap and $\mathrm{H}_{2}$ evolution rate of mPSi materials and $\mathrm{Si}$ nanopowder.

Hydrogen generation by chemical reactions of mPSi-600R. Measurements of $\mathrm{H}_{2}$ generation over time were obtained by digital video analysis of gas evolution. Twenty-five millilitres of Schlenk flasks with a glass stopcock was used for the reactions. The $\mathrm{H}_{2}$ generation rates demonstrated by chemical reaction of $\mathrm{mPSi}$ $600 \mathrm{R}$ with $\mathrm{KOH}$ aqueous solution are also largely repeatable $(0.095,0.070,0.078$ and $0.091 \mathrm{~g} \mathrm{H}_{2} \mathrm{~s}^{-1} \mathrm{~g}^{-1} \mathrm{Si}$, as measured in four separate tests, Supplementary Fig. 9). The reactions went to completion within $4 \mathrm{~s}$, allowing the total $\mathrm{H}_{2}$ generation amount to be compared with the stoichiometric amount. Total $\mathrm{H}_{2}$ yields in terms of $\mathrm{mol} \mathrm{H}_{2} \mathrm{~mol}^{-1} \mathrm{Si}$ are in the range of $1.6-1.8 \mathrm{~mol} \mathrm{H}_{2} \mathrm{~mol}^{-1} \mathrm{Si}$. This is smaller than the stoichiometric yield $\left(2 \mathrm{~mol} \mathrm{H}_{2} \mathrm{~mol}^{-1} \mathrm{Si}\right)$ owing to mPSi-600R containing some $\mathrm{Si}$ oxides, which has been proved by other characterization. As oxidized silicon can produce less or no hydrogen by reaction with $\mathrm{KOH}$ aqueous solution (depending on its degree of oxidation), it is reasonable that mPSi-600R has a below-stoichiometric $\mathrm{H}_{2}$ yield. The average reaction rate of the full reaction process is $0.04-0.07 \mathrm{~g} \mathrm{H}_{2} \mathrm{~s}^{-1} \mathrm{~g}^{-1} \mathrm{Si}\left(0.56-0.98 \mathrm{~mol} \mathrm{H}_{2} \mathrm{~s}^{-1} \mathrm{~mol}^{-1} \mathrm{Si}\right)$.

\section{References}

1. Stewart, M. P. \& Buriak, J. M. Chemical and biological applications of porous silicon technology. Adv. Mater. 12, 859-869 (2000).

2. Cullis, A. G. \& Canham, L. T. Visible light emission due to quantum size effects in highly porous crystalline silicon. Nature 353, 335-338 (1991).

3. Lin, V. S., Motesharei, K., Dancil, K. P., Sailor, M. J. \& Ghadiri, M. R. A porous silicon-based optical interferometric biosensor. Science 278, 840-843 (1997).

4. Li, Y. Y. et al. Polymer replicas of photonic porous silicon for sensing and drug delivery applications. Science 299, 2045-2047 (2003).

5. Magasinski, A. et al. High-performance lithium-ion anodes using a hierarchical bottom-up approach. Nat. Mater. 9, 353-358 (2010).

6. Kim, H., Han, B., Choo, J. \& Cho, J. Three-dimensional porous silicon particles for use in high-performance lithium secondary batteries. Angew. Chem. Int. Ed. 47, 10151-10154 (2008)

7. Erogbogbo, F. et al. On-demand hydrogen generation using nanosilicon: splitting water without light, heat, or electricity. Nano Lett. 13, 451-456 (2013).

8. Mathews, N. R., Sebastian, P. J., Mathew, X. \& Agarwal, V. Photoelectrochemical characterization of porous Si. Int. J. Hydrogen Energy 28, 629-632 (2003).

9. Bahruji, H., Bowker, M. \& Davies, P. R. Photoactivated reaction of water with silicon nanoparticles. Int. J. Hydrogen Energy 34, 8504-8510 (2009).

10. Canham, L. T. Properties of Porous Silicon (INSPEC, Institution of Engineering \& Technology, 1997).

11. Bao, Z. et al. Chemical reduction of three-dimensional silica micro-assemblies into microporous silicon replicas. Nature 446, 172-175 (2007).

12. Richman, E. K., Kang, C. B., Brezesinski, T. \& Tolbert, S. H. Ordered mesoporous silicon through magnesium reduction of polymer templated silica thin films. Nano Lett. 8, 3075-3079 (2008).
13. Wang, J. F. et al. Amorphous silicon with high specific surface area prepared by a sodiothermic reduction method for supercapacitors. Chem. Commun. 49, 5007-5009 (2013).

14. Evanoff, K., Magasinski, A., Yang, J. \& Yushin, G. Nanosilicon-coated graphene granules as anodes for Li-ion batteries. Adv. Energy Mater. 1, 495-498 (2011)

15. Kanatzidis, M. G. Beyond silica: nonoxidic mesostructured materials. Adv Mater. 19, 1165-1181 (2007).

16. Ren, Y., Ma, Z. \& Bruce, P. G. Ordered mesoporous metal oxides: synthesis and applications. Chem. Soc. Rev. 41, 4909-4927 (2012).

17. Yanagisawa, T., Shimizu, T., Kuroda, K. \& Kato, C. The Preparation of The preparation of alkyltrimethylammonium-kanemite complexes and their conversion to microporous materials. Bull. Chem. Soc. Jpn 63, 988-992 (1990)

18. Kresge, C. T., Leonowicz, M. E., Roth, W. J., Vartuli, J. C. \& Beck, J. S. Ordered mesoporous molecular sieves synthesized by a liquid-crystal template mechanism. Nature 359, 710-712 (1992).

19. Beck, J. S. et al. A new family of mesoporous molecular sieves prepared with liquid crystal templates. J. Am. Chem. Soc. 114, 10834-10843 (1992).

20. Tian, Z.-R. et al. Manganese oxide mesoporous structures: mixed-valent semiconducting catalysts. Science 276, 926-930 (1997).

21. Armatas, G. S. \& Kanatzidis, M. G. Mesostructured germanium with cubic pore symmetry. Nature 441, 1122-1125 (2006).

22. Armatas, G. S. \& Kanatzidis, M. G. Hexagonal mesoporous germanium. Science 313, 817-820 (2006).

23. Sun, D. et al. Hexagonal nanoporous germanium through surfactant-driven self-assembly of Zintl clusters. Nature 441, 1126-1130 (2006).

24. Armatas, G. S. \& Kanatzidis, M. G. Mesoporous germanium-rich chalcogenido frameworks with highly polarizable surfaces and relevance to gas separation. Nat. Mater. 8, 217-222 (2009).

25. Kornowski, A., Giersig, M., Vogel, R., Chemseddine, A. \& Weller, H. Nanometer-sized colloidal germanium particles: wet-chemical synthesis, laserinduced crystallization and particle growth. Adv. Mater. 5, 634-636 (1993).

26. Heath, J. R. A liquid-solution-phase synthesis of crystalline silicon. Science 258, 1131-1133 (1992).

27. Bley, R. A. \& Kauzlarich, S. M. A low-temperature solution phase route for the synthesis of silicon nanoclusters. J. Am. Chem. Soc. 118, 12461-12462 (1996)

28. Yang, C.-S., Bley, R. A., Kauzlarich, S. M., Lee, H. W. H. \& Delgado, G. R. Synthesis of alkyl-terminated silicon nanoclusters by a solution route. J. Am. Chem. Soc. 121, 5191-5195 (1999).

29. Mayeri, D., Phillips, B. L., Augustine, M. P. \& Kauzlarich, S. M. NMR study of the synthesis of alkyl-terminated silicon nanoparticles from the reaction of $\mathrm{SiCl}_{4}$ with the zintl salt, NaSi. Chem. Mater. 13, 765-770 (2001).

30. Baldwin, R. K. et al. Room temperature solution synthesis of alkyl-capped tetrahedral shaped silicon nanocrystals. J. Am. Chem. Soc. 124, 1150-1151 (2002).

31. Wilcoxon, J. P., Samara, G. A. \& Provencio, P. N. Optical and electronic properties of Si nanoclusters synthesized in inverse micelles. Phys. Rev. B 60, 2704-2714 (1999)

32. Kim, S. H., Liu, B. Y. H. \& Zachariah, M. R. Synthesis of nanoporous metal oxide particles by a new inorganic matrix spray pyrolysis method. Chem. Mater. 14, 2889-2899 (2002).

33. Peterson, A. K., Morgan, D. G. \& Skrabalak, S. E. Aerosol synthesis of porous particles using simple salts as a pore template. Langmuir 26, 8804-8809 (2010).

34. Ruike, M. et al. Pore structure of porous silicon formed on a lightly doped crystal silicon. Langmuir 12, 4828-4831 (1996).

35. Chen, F., Zai, J., Xu, M. \& Qian, X. 3D-hierarchical $\mathrm{Cu}_{3} \mathrm{SnS}_{4}$ flowerlike microspheres: controlled synthesis, formation mechanism and photocatalytic activity for $\mathrm{H}_{2}$ evolution from water. J. Mater. Chem. A 1, 4316-4323 (2013).

36. Tsuji, I., Kato, H., Kobayashi, H. \& Kudo, A. Photocatalytic $\mathrm{H}_{2}$ evolution reaction from aqueous solutions over band structure-controlled (AgIn) $\mathrm{Zn}_{2}$ $(1-x) S_{2}$ solid solution photocatalysts with visible-light response and their surface nanostructures. J. Am. Chem. Soc. 126, 13406-13413 (2004).

37. Xiang, Q., Yu, J. \& Jaroniec, M. Synergetic effect of $\mathrm{MoS}_{2}$ and graphene as cocatalysts for enhanced photocatalytic $\mathrm{H}_{2}$ production activity of $\mathrm{TiO}_{2}$ nanoparticles. J. Am. Chem. Soc. 134, 6575-6578 (2012).

38. Baldwin, R. K., Pettigrew, K. A., Ratai, E., Augustine, M. P. \& Kauzlarich, S. M. Solution reduction synthesis of surface stabilized silicon nanoparticles. Chem. Commun. 1822-1823 (2002).

39. Dai, F., Yi, R., Gordin, M. L., Chen, S. \& Wang, D. Amorphous $\mathrm{Si}_{/} \mathrm{SiO}_{\mathrm{x}} / \mathrm{SiO}_{2}$ nanocomposites via facile scalable synthesis as anode materials for $\mathrm{Li}$-ion batteries with long cycling life. RSC Adv. 2, 12710-12713 (2012).

40. Sing, K. S. W. et al. Reporting physisorption data for gas solid systems with special reference to the determination of surface-area and porosity. Pure Appl. Chem. 57, 603-619 (1985).

41. Gautam, D., Koyanagi, E. \& Uchino, T. Photoluminescence properties of $\mathrm{SiO}_{x}$ thin films prepared by reactive electron beam evaporation from $\mathrm{SiO}$ and silica nanoparticles. J. Appl. Phys. 105, 073517 (2009).

42. Alfonsetti, R. et al. $\mathrm{SiO}_{\mathrm{x}}$ surface stoichiometry by XPS: A comparison of various methods. Surf. Interface Anal 22, 89-92 (1994). 
43. Shallenberger, J. R. Determination of chemistry and microstructure in $\mathrm{SiO}_{\mathrm{x}}$ $(0.1<\mathrm{x}<0.8)$ films by X-ray photoelectron spectroscopy. J. Vac. Sci. Technol. A 14, 693-698 (1996).

44. Hernández, S. et al. Silicon nanocluster crystallization in $\mathrm{SiO}_{\mathrm{x}}$ films studied by Raman scattering. J. Appl. Phys. 104, 044304 (2008).

45. Yi, R., Dai, F., Gordin, M. L., Chen, S. \& Wang, D. Micro-sized Si-C composite with interconnected nanoscale building blocks as high-performance anodes for practical application in lithium-ion batteries. Adv. Energy Mater. 3, 295-300 (2013).

46. Iqbal, Z. \& Veprek, S. Raman-scattering from hydrogenated microcrystalline and amorphous-silicon. J. Phys. C Solid State Phys. 15, 377-392 (1982).

47. Wang, R. P. et al. Raman spectral study of silicon nanowires: high-order scattering and phonon confinement effects. Phys. Rev. B 61, 16827-16832 (2000).

48. Voutsas, A. T., Hatalis, M. K., Boyce, J. \& Chiang, A. Raman spectroscopy of amorphous and microcrystalline silicon films deposited by low-pressure chemical vapor deposition. J. Appl. Phys. 78, 6999-7006 (1995).

49. Mawhinney, D. B., Glass, J. A. \& Yates, J. T. FTIR study of the oxidation of porous silicon. J. Phys. Chem. B 101, 1202-1206 (1997).

50. Cortright, R. D., Davda, R. R. \& Dumesic, J. A. Hydrogen from catalytic reforming of biomass-derived hydrocarbons in liquid water. Nature 418, 964-967 (2002).

51. Kudo, A. \& Miseki, Y. Heterogeneous photocatalyst materials for water splitting. Chem. Soc. Rev. 38, 253-278 (2009).

52. Osterloh, F. E. Inorganic materials as catalysts for photochemical splitting of water. Chem. Mater. 20, 35-54 (2007).

53. Qu, Y. \& Duan, X. Progress, challenge and perspective of heterogeneous photocatalysts. Chem. Soc. Rev. 42, 2568-2580 (2013).

54. Liu, R. et al. Silicon nanowires as photoelectrodes for carbon dioxide fixation. Angew. Chem. Int. Ed. 51, 6709-6712 (2012).

55. Yang, T., Wang, H., Ou, X. M., Lee, C. S. \& Zhang, X. H. Iodine-dopedpoly(3,4-ethylenedioxythiophene)-modified Si nanowire 1D core-shell arrays as an efficient photocatalyst for solar hydrogen generation. Adv. Mater. 24, 6199-6203 (2012)

56. Hou, Y. et al. Bioinspired molecular co-catalysts bonded to a silicon photocathode for solar hydrogen evolution. Nat. Mater. 10, 434-438 (2011)

57. Oh, I., Kye, J. \& Hwang, S. Enhanced photoelectrochemical hydrogen production from silicon nanowire array photocathode. Nano Lett. 12, 298-302 (2012).

58. Liu, G., Niu, P. \& Cheng, H. M. Visible-light-active elemental photocatalysts. Chem. Phys. Chem. 14, 885-892 (2013).

59. Li, M., Li, J. C. \& Jiang, Q. Size-dependent band-gap and dielectric constant of Si nanocrystals. Int. J. Mod. Phys. B 24, 2297-2301 (2010).

60. Delerue, C., Allan, G. \& Lannoo, M. Theoretical aspects of the luminescence of porous silicon. Phys. Rev. B 48, 11024-11036 (1993).

61. Kux, A. \& Ben Chorin, M. Band gap of porous silicon. Phys. Rev. B 51, 17535-17541 (1995)

62. Bateman, J. E., Eagling, R. D., Horrocks, B. R., Houlton, A. \& Worrall, D. R. Rôle for organic molecules in the oxidation of porous silicon. Chem. Commun. 2275-2276 (1997).

63. Iyengar, V. V., Nayak, B. K. \& Gupta, M. C. Optical properties of silicon light trapping structures for photovoltaics. Sol. Energy Mater. Sol. Cell 94, 2251-2257 (2010).
64. Dubey, R. S. \& Sarojini, P. L. Light trapping mechanism in one-dimensional (1D) photonic crystals for silicon-based solar cells. J. Electromagnet. Wave 27, 309-317 (2013).

65. Cui, Y., Zhong, Z., Wang, D., Wang, W. U. \& Lieber, C. M. High performance silicon nanowire field effect transistors. Nano Lett. 3, 149-152 (2003).

66. Iwase, A., Ng, Y. H., Ishiguro, Y., Kudo, A. \& Amal, R. Reduced graphene oxide as a solid-state electron mediator in Z-scheme photocatalytic water splitting under visible light. J. Am. Chem. Soc. 133, 11054-11057 (2011).

67. Tawada, Y., Kondo, M., Okamoto, H. \& Hamakawa, Y. Hydrogenated amorphous silicon carbide as a window material for high efficiency a-Si solar cells. Sol. Energy Mater. 6, 299-315 (1982).

68. Alexander, M. R., Short, R. D., Jones, F. R., Michaeli, W. \& Blomfield, C. J. A study of $\mathrm{HMDSO} / \mathrm{O}_{2}$ plasma deposits using a high-sensitivity and -energy resolution XPS instrument: curve fitting of the Si 2p core level. Appl. Surf. Sci. 137, 179-183 (1999).

69. Iwata, S. \& Ishizaka, A. Electron spectroscopic analysis of the $\mathrm{SiO}_{2} / \mathrm{Si}$ system and correlation with metal-oxide-semiconductor device characteristics. J. Appl. Phys. 79, 6653-6713 (1996).

\section{Acknowledgements}

This work was supported by the Pennsylvania Keystone Innovation Starter Kit Fund, the Defense Threat Reduction Agency Fund (HDTRA1-10-1-0094) and the United States Department of Energy Fund (DE-AC02-05CH11231/695137). The Raman spectroscopy study was supported by the Pennsylvania State University Materials Research Institute NanoFabrication Network and the National Science Foundation Cooperative Agreement number 0335765, National Nanotechnology Infrastructure Network, with Cornell University. We thank Dr Vincent Bojan for his help with XPS characterization, Dr Ke Wang for HRTEM microscopy characterization and Professor Christine D Keating and $\mathrm{Mr}$ William Aumiller for providing the fluorimeter and their kind help with fluorescence spectroscopy. We also thank Dr Jingmei Shen and Mr Kai Han from Northwestern University for their help with XPS spectroscopy.

\section{Author contributions}

D.W. conceived the experiment, supervised the research work and was involved in scientific discussions. F.D. designed and carried out the syntheses. J.Z. performed photocatalysis measurements. R.Y., H.S., S.C. and M.L.G. performed characterizations. F.D., J.Z., R.Y., M.L.G. and D.W. participated in the preparation of the manuscript.

\section{Additional information}

Supplementary Information accompanies this paper at http://www.nature.com/ naturecommunications

Competing financial interests: The authors declare no competing financial interests.

Reprints and permission information is available online at http://npg.nature.com/ reprintsandpermissions/

How to cite this article: Dai, F. et al. Bottom-up synthesis of high surface area mesoporous crystalline silicon and evaluation of its hydrogen evolution performance. Nat. Commun. 5:3605 doi: 10.1038/ncomms4605 (2014). 